\title{
Effects of adsorption of copper-polluted water by Ti-MCM-41
}

\author{
Xiangqing Fang1, a , Le Sun ${ }^{2, b}$ and $\mathrm{Ya} \mathrm{Li}^{3, \mathrm{c}}$ \\ ${ }^{1}$ Xi'an Aeronautical University, Xi'an 710077, China \\ ${ }^{2}$ Xi'an Aeronautical University, Xi'an 710077, China \\ ${ }^{3}$ Xi'an Aeronautical University, Xi'an 710077, China \\ afancy0710@163.com, b1528172152@qq.com, c409296371@qq.com
}

\begin{abstract}
Keywords: Ti-MCM-41; $\mathrm{Cu}(\mathrm{II})$ ion; adsorption rate; adsorption capacity
Abstract. Ti-MCM-41 zeolite was hydrothermally synthesized by using tetrabutyl orthotitanate as titanium source and fumed silica as silicon. Powder X-ray diffraction UV-vis diffuse reflectance spectroscopy and inductively coupled plasma were used to characterize the product, results indicated revealed that the Ti-MCM-41 material was synthesized sucessfully with ordered hexagonal structure. Ti-MCM-41 zeolite was used to investigate the effects of contact time, adsorption temperature, $\mathrm{pH}$ value and reusibility on the adsorption of $\mathrm{Cu}$ (II). The results showed that the optimal adsorption conditions were: contact time was $60 \mathrm{~min}$, adsorption temperature was $333 \mathrm{~K}$ and pH value was 6 for the initial $\mathrm{Cu}$ (II) concentration of $50 \mathrm{mg} / \mathrm{L}$. The adsoption rate and adsorption capacity of $\mathrm{Cu}$ (II) were $90.52 \%$ and $45.26 \mathrm{mg} / \mathrm{g}$, respectively. In the meantime, Ti-MCM-41 showed outstanding reusability on adsorption of $\mathrm{Cu}(\mathrm{II})$.
\end{abstract}

\section{Introduction}

In recent years, metal pollution in ground water, mainly with copper, is increasing. The removal of $\mathrm{Cu}(\mathrm{II})$ ions in water is currently a strategic issue. Among all the water processing methods, the adsorption method received the most attention bacause its high-efficiency, versatile, economical and easy operation etc [1,2]. MCM-41 zeolite possess well-ordered, hexagonal array of pore channels and tunable pore size, has attracted considerable attention due to its potential applications in catalysis, separation, and adsorption for heavy metals [3,4]. Unfortunately, MCM-41 zeolite is liable to collapse when exposed to boiling water or mechanically compressed due to the amorphous frameworks and thin walls $[5,6]$. The hydrothermal stability of MCM-41 can be enhanced by implanted Ti into the framework [7]. However, the literature studies on the adsorption of $\mathrm{Cu}(\mathrm{II})$ with Ti-MCM-41 are very limited.

In this report, Ti-MCM-41 was synthesized by hydrothermal method [8], X-ray diffraction, UV-vis diffuse reflectance spectroscopy and inductively coupled plasma were used to characterize the prepared material. The synthesized Ti-MCM-41 zeolite was used for adsorption of $\mathrm{Cu}$ (II) in aqueous solution. The optimum adsorption conditions for the adsorption of $\mathrm{Cu}$ (II) have been established and reusability of Ti-MCM-41 was investigated.

\section{Material and methods}

Synthesis of Ti-MCM-41. Following previous procedures [8], Ti-MCM-41 was hydrothermally synthesized use cetyltrimethylammonium tosylate (CTATos, 99\%) as a structure-directing agent. In a typical synthesis, $3.3 \mathrm{~g}$ CTATos was dissolved in $60 \mathrm{~mL}$ water and stirred for $2 \mathrm{~h}$ at $353 \mathrm{~K} .10 .43 \mathrm{~g}$ tetramethylammonium hydroxide (TMAOH, 25\%) aqueous solution was added into $48 \mathrm{~mL}$ water, followed by $4.88 \mathrm{~g}$ fumed silica under vigorous agitation. The silicate solution was stirred for $2 \mathrm{~h}$ at $353 \mathrm{~K}$ and cooled to $273 \mathrm{~K}$, then tetrabutyl titanate (TBOT, 98\%) isopropanol solution containing $0.92 \mathrm{~g}$ TBOT and $2 \mathrm{~g}$ isopropanol was added slowly and continued to stir for $50 \mathrm{~min}$ at $273 \mathrm{~K}$. Alcohol was removed by stirring at $333 \mathrm{~K}$ for $2 \mathrm{~h}$ and the water content was adjusted. The above mixture was dropwise added into CTATos solution. The gels with the molar compositions of $\mathrm{SiO}_{2}: 1 / 30 \mathrm{TiO}_{2}$ : 0.09 CTATos: 0.35 TMAOH: $82 \mathrm{H}_{2} \mathrm{O}$ were stirred continuously for $2 \mathrm{~h}$ at $353 \mathrm{~K}$ and then heated in 
autoclave under static condition at $443 \mathrm{~K}$ for 2 days. The product was filtered, washed with amounts of distilled $\mathrm{H}_{2} \mathrm{O}$, dried at $373 \mathrm{~K}$ overninght and finally calcined in air at $823 \mathrm{~K}$ for $6 \mathrm{~h}$.

Recovery of Ti-MCM-41. The used Ti-MCM-41 zeolite was separated by centrifugation (at $3000 \mathrm{rpm}$ for $5 \mathrm{~min}$ ) and the residual solid was dried at $353 \mathrm{~K}$. Then the zeolite was added to $100 \mathrm{~mL}$ of the $\mathrm{HCl}$ with the concentration of $1 \mathrm{~mol} / \mathrm{L}$, stirred $8 \mathrm{~h}$, filtered, washed with distilled $\mathrm{H}_{2} \mathrm{O}$, dried at 373 K overninght.

Adsorption Experiments. The $\mathrm{Cu}$ (II) adsorption experiments were performed by batch technique to obtain the adsorption rate and adsorption capacity. A fixed amount of Ti-MCM-41 zeolite $(0.05 \mathrm{~g})$ was taken in stoppered conical flasks, $50 \mathrm{~mL}$ of $\mathrm{Cu}$ (II) solutions with concentration of $50 \mathrm{mg} / \mathrm{L}$ was added. The solution $\mathrm{pH}$ value was adjusted by using $0.1 \mathrm{~mol} / \mathrm{L} \mathrm{HCl}$ and $0.1 \mathrm{~mol} / \mathrm{L}$ $\mathrm{NH}_{4} \mathrm{OH}$. The mixture was stirred vigorously by using a magnetic stirrer at $200 \mathrm{rpm}$ for different contact time at different temperatures. After adsorption, the mixture was centrifuged and the amount of $\mathrm{Cu}$ (II) ions in the solution was measured by atomic absorption spectroscopy. The adsoption rate (Q) and adsorption capacity $\left(q_{\mathrm{e}}\right)$ were calculated from the equation 1 and 2 , respectively.

$$
\begin{aligned}
& \mathrm{Q}=\left(c_{0}-c_{e}\right) / c_{0} \times 100 \% . \\
& q_{\mathrm{e}}=\left(c_{0}-c_{e}\right) / m \times V \times 0.001 .
\end{aligned}
$$

Where $\mathrm{Q}(\%)$ is the the adsoption rate, $q_{\mathrm{e}}(\mathrm{mg} / \mathrm{g})$ is the adsorption capacity, $c_{0}(\mathrm{mg} / \mathrm{L})$ is the initial concentrations of $\mathrm{Cu}(\mathrm{II})$ ions, $c_{\mathrm{e}}(\mathrm{mg} / \mathrm{L})$ represent the equilibrium concentrations of $\mathrm{Cu}(\mathrm{II})$ ions, $m(\mathrm{~g})$ is the weightof Ti-MCM-41 and $V(\mathrm{~L})$ is the solution volume.

\section{Results and discussions}

Characterization of Ti-MCM-41. The XRD pattern of Ti-MCM-41 is presented in Fig. 1a. There are three well-resolved intense peaks as (100), (110) and (200) [3], confirming well-ordered hexagonal mesoporous structure. This result indicates that the Ti-MCM-41 zeolite as-synthesized was highly crystalline materials with a pure phase. The UV-visible spectra of Ti-MCM-41 is shown in Fig. 1b. The absorption of Ti-MCM-41 exhibits a characteristic main band at $210 \mathrm{~nm}$ together with a weak shoulder around $260 \mathrm{~nm}$, which indicates that the Ti atoms are incorporated into the framwork of the MCM-41 hexagonal structure and highly dispersed as the isolated tetrahedrally coordinated Ti species $[9,10]$. The ICP results revealed that the Si/Ti molar ratio of Ti-MCM-41 was 43.
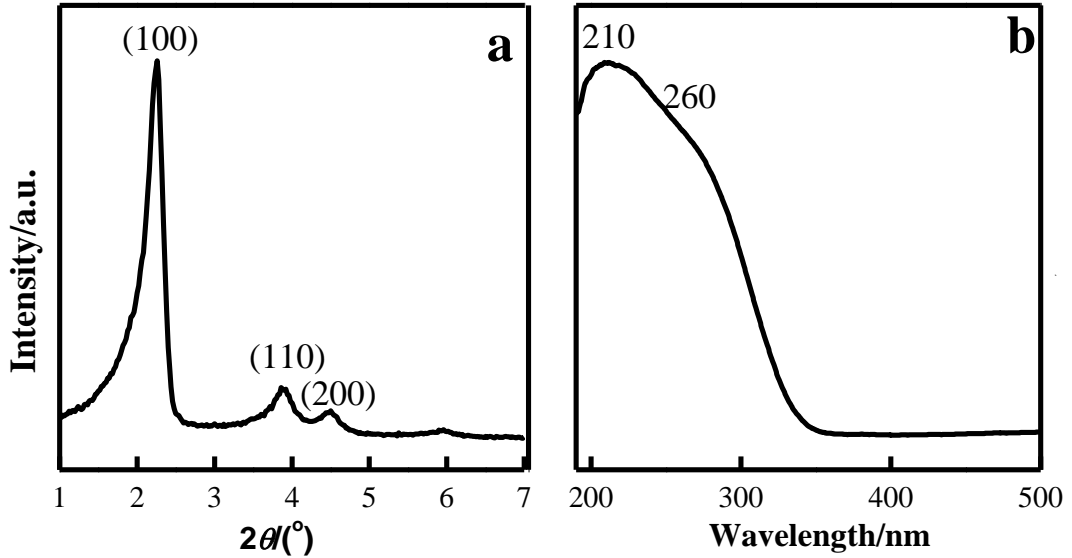

Fig.1 X-Ray diffraction pattern (a) and UV-Vis spectrums (b) of Ti-MCM-41.

Effect of contact time. Fig. 2 shows the effect of contact time intervals ranging from 0 to $80 \mathrm{~min}$ on the adsorption of $\mathrm{Cu}(\mathrm{II})$ by Ti-MCM-41 zeolite. It is apparent that contact time has significant influence on the adsorption efficiency. The experiments showed (Fig. 2) rapid adsorption of $\mathrm{Cu}$ (II) within the initial $50 \mathrm{~min}$ and the equilibrium was observed at $60 \mathrm{~min}$ with the adsoption rate and adsorption capacity reaching $90.52 \%$ and $45.26 \mathrm{mg} / \mathrm{g}$. A further increase in contact time to $80 \mathrm{~min}$ had a slightly effect on the $\mathrm{Cu}$ (II) removal. At the beginning of adsorption, plenty of available vacant adsorption sites on the surface of Ti-MCM-41 were gradually decreased. $\mathrm{Cu}$ (II) was not strongly adsorbed by absorbent due to the repulsive forces between inside the aqueous phase and solute 
molecules on the surface. Therefore, the minimum contact time of 60 min could be considered for optimum adsorption of $\mathrm{Cu}$ (II) on Ti-MCM-41.

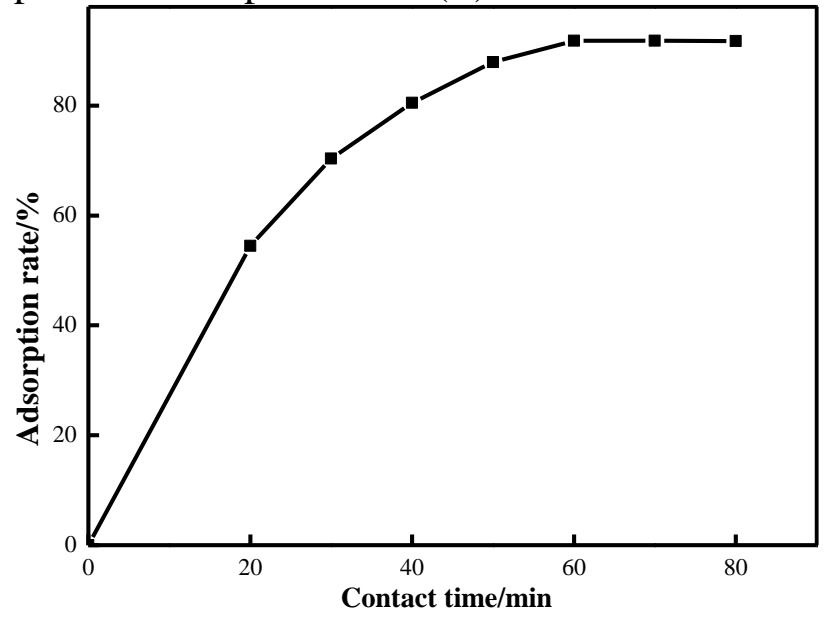

Fig. 2 Effect of contact time on the adsorption of $\mathrm{Cu}(\mathrm{II})$.

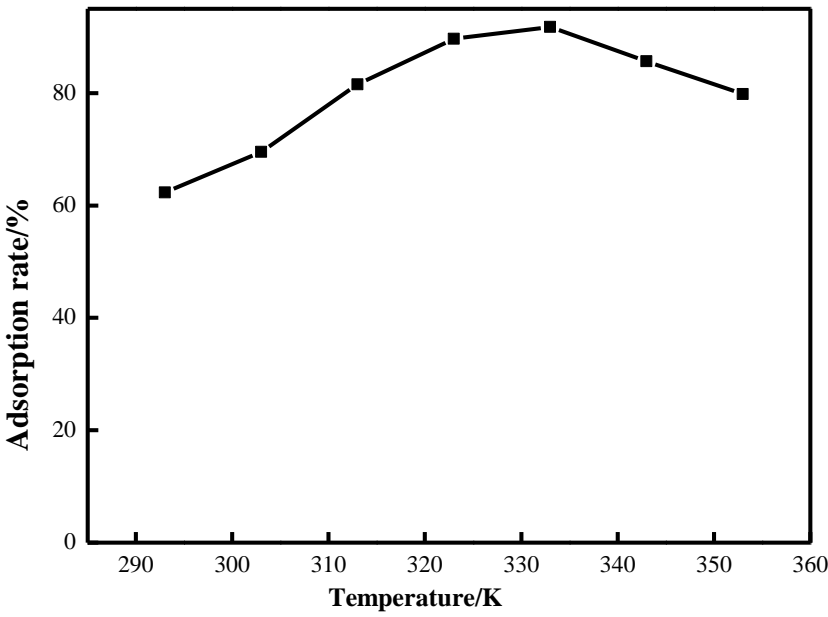

Fig. 3 Effect of temperature on the adsorption of $\mathrm{Cu}(\mathrm{II})$.

Effect of adsorption temperature. The adsorption of $\mathrm{Cu}$ (II) on Ti-MCM-41 was studied at temperatures of 293, 303, 313, 323, 333 and 343K. As shown in Fig. 3, the adsorption of $\mathrm{Cu}$ (II) significantly increased with rise in temperature from 293 to $333 \mathrm{~K}$. The increased adsorption may be attributed to enhanced rate of intraparticle diffusion [11], which indicated that adsorption of $\mathrm{Cu}$ (II) on Ti-MCM-41 was an endothermic process. However, when the temperature was further increased (> $333 \mathrm{~K}$ ), the adsorption of $\mathrm{Cu}$ (II) decreased slowly. As the temperature increased, the mobility of $\mathrm{Cu}$ (II) increasesd causing the ions to escaped from Ti-MCM-41zeolite to the liquid phase. Therefore, the desorption of $\mathrm{Cu}$ (II) occupied a leading position. Hence, we chose $333 \mathrm{~K}$ as the suitable adsorption temperature.

Effect of $\mathbf{p H}$ value. The soluble copper is in favor of $\mathrm{Cu}$ (II) ions (blue) at lower $\mathrm{pH}$ but it shifts to $\mathrm{Cu}(\mathrm{OH})_{2}$ (dark brown) when the $\mathrm{pH}$ is more than 7 [12]. In order to determine the effect of $\mathrm{pH}$ value on the adsorption capacity of Ti-MCM-41, solutions were prepared at various $\mathrm{pH}$ values ranging from 20 to 6.0 (Fig. 4). It is found that the adsorption of $\mathrm{Cu}$ (II) obvious increased from $\mathrm{pH}=2$ to $\mathrm{pH}=6$. This attribute to high concentrations of $\mathrm{H}^{+}$could bonding with $\mathrm{Si}-\mathrm{OH}$ and $\mathrm{Ti}-\mathrm{OH}$ groups, which decreased the number of charged sites (such as $\mathrm{Si}-\mathrm{OH}$ and $\mathrm{Ti}-\mathrm{OH}$ groups)and reduces the attraction between $\mathrm{Cu}$ (II) and adsorbent surface [13]. The strong $\mathrm{pH}$ dependent adsorption of of $\mathrm{Cu}$ (II) on Ti-MCM-41 indicated that the process is dominated by surface complexation.

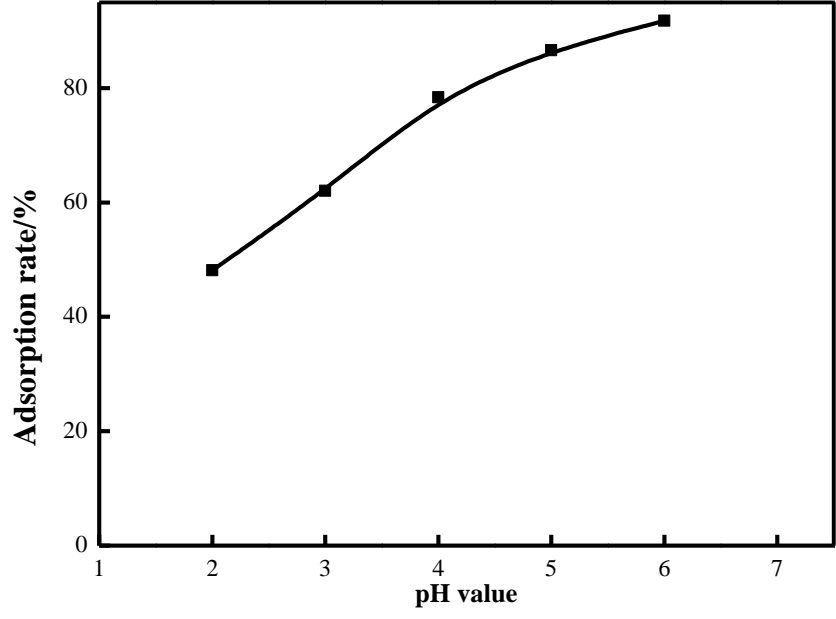

Fig. 4 Effect of $\mathrm{pH}$ value on the adsorption of $\mathrm{Cu}(\mathrm{II})$.

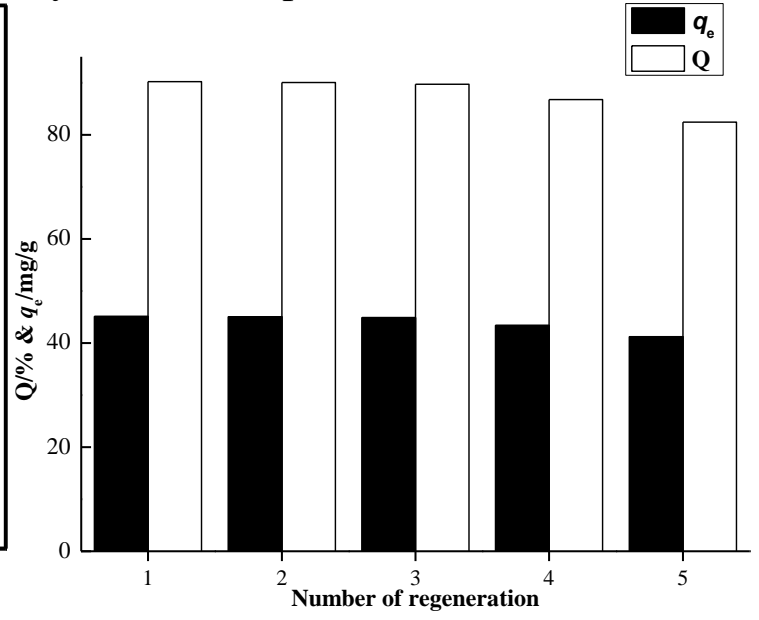

Fig. 5 The adsorption-regeneration cycles of Ti-MCM-41.

Reusability of Ti-MCM-41. In addition to adsorption capacity, the applicability of sorbents depends also on their reusability. Ti-MCM-41 was first reused on the adsorption of $\mathrm{Cu}(\mathrm{II})$. The experiments were initiated with an enlarged adsorbent dosage of $1 \mathrm{~g}$, the $\mathrm{Cu}$ (II) ions adsorbed onto 
Ti-MCM-41 were eluted out by $\mathrm{HCl}$. Then, it was subjected to a repeated process at a constant ratio of absorbent-adsorbate. The adsorption-desorption cycle (Fig. 5) results indicated that the Ti-MCM-41 could be reused up to 6 times without a significant decrease in the adsorption of $\mathrm{Cu}(\mathrm{II})$, the adsoption rate and adsorption capacity maintained as $82.42 \%$ and $41.21 \mathrm{mg} / \mathrm{g}$, respectively. Therefore, Ti-MCM-41 have potential practical application prospect for the removal of $\mathrm{Cu}(\mathrm{II})$ from water and wastewater.

\section{Conclusion}

The results suggest that the adsorption of $\mathrm{Cu}(\mathrm{II})$ is influenced by the contact time, the adsorption temperature and the solution $\mathrm{pH}$ value. The adsorption reached the equilibrium when contact time was $60 \mathrm{~min}$, the optimized adsorption temperature was $333 \mathrm{~K}$ and the best $\mathrm{pH}$ value was 6 . The maximum adsoption rate and adsorption capacity of $\mathrm{Cu}$ (II) ions with Ti-MCM-41 90.52\% and 45.26 $\mathrm{mg} / \mathrm{g}$, respectively. Furthermore, Ti-MCM-41 possessed excellent reusability on the adsorption of $\mathrm{Cu}(\mathrm{II})$, which have good prospects for the removal of $\mathrm{Cu}$ (II) from water and wastewater in practical application.

\section{Acknowledgements}

This work was financially supported by the National Natural Science Foundation of China (21503154), Science Foundation of Shaanxi Province of China (2016JQ2001) and Educational Commission of Shaanxi Province of China (15JK1373, 16JK1393).

\section{References}

[1] A. Benhamou, M. Baudu, Z. Derriche and J. P. Basly. J. Hazard. Mater. Vol. 171 (2009), p. 1001.

[2] K. Parida, K. G. Mishra and S. K. Dash. Ind. Eng. Chem. Res. Vol. 51 (2012), p. 2235.

[3] A. Corma, M. T. Navarro and J. P. Pariente. J. Chem. Soc., Chem. Commun. Vol. 2(1994), p. 147.

[4] S. Morin, P. Ayrault, S. E. Mouahid, N. S. Gnep and M. Guisnet. Appl. Catal. A: Gen. Vol. 159 (1997), p. 317.

[5] M. E. Davis. Nature. Vol. 364 (1993), p. 391.

[6] S. Jun, J. M. Kim, R. Ryoo, Y. S. Ahn and M. H. Han. Micropor. Mesopor. Mater. Vol. 41 (2000), p. 119.

[7] P. Schacht, L. Noreña-Franco, J. Ancheyta, S. Ramírez, I. Hernández-Pérez and L. A. Garcíaa. Catal. Today. Vol. 47 (1999), p. 115.

[8] H. L. Chen, K. Zhang and Y. M. Wang. Mater. Res. Bull. Vol. 47 (2012), p. 1774.

[9] Y. Belmabkhout and A. Sayari. Energy Fuels. Vol. 24 (2010), p. 5273.

[10] Y. Hua, S. Higashimotoa, G. Martrab, J. Zhang, M. Matsuokaa, S. Colucciab and M. Anpo. Catal. Lett. Vol. 90 (2003), p. 161.

[11] W. S. W. Ngah and M. A. K. M. Hanafiah. Biochem. Eng. J. Vol. 39 (2008), p. 521.

[12] L. Hidmi and M. Edwards. Environ. Sci. Technol. Vol. 33 (1999), p. 2607.

[13] C. L. Chen and X. K. Wang. Appl. Radiat. Isotopes. Vol. 65 (2007), p. 155. 